\title{
Patulin, Deoxynivalenol, Zearalenone and T-2 Toxin Affect Viability and Modulate Cytokine Secretion in J774A.1 Murine Macrophages
}

\author{
Jonathan H. Loftus ${ }^{1,3}$, Gregor S. Kijanka ${ }^{2}$, Richard O'Kennedy ${ }^{1,2}$, Christine E. Loscher ${ }^{3}$ \\ ${ }^{1}$ Applied Biochemistry Group, School of Biotechnology, Dublin City University, Dublin 9, Ireland \\ ${ }^{2}$ Biomedical Diagnostics Institute, Dublin City University, Dublin 9, Ireland \\ ${ }^{3}$ Immunomodulation Group, School of Biotechnology, Dublin City University, Dublin 9, Ireland \\ Correspondence: Christine Loscher, Immunomodulation Group, School of Biotechnology, Dublin City University, \\ Dublin 9, Ireland. Tel: +35317006290 E-mail: christine.loscher@dcu.ie
}

Received: January 6, 2016 Accepted: February 29, 2016 Online Published: March 10, 2016

doi:10.5539/ijc.v8n2p22 URL: http://dx.doi.org/10.5539/ijc.v8n2p22

\begin{abstract}
Mycotoxins are secondary fungal metabolites, which occur in food and feed. They have detrimental effects on the health of humans and animals, and they are known to cause immunosuppression. In this study the effect of patulin, deoxynivalenol (DON), zearalenone (ZEN) and T-2 toxin exposure on the viability and the secretion of key pro- and anti-inflammatory cytokines from the murine macrophage cell line, J774A.1, was investigated. Exposure of macrophages to high doses of ZEN $(100,000 \mathrm{pg} / \mathrm{mL})$ and T-2 toxin $(10,000$ and $100,000 \mathrm{pg} / \mathrm{mL})$ resulted in a significant decrease $(\mathrm{P}<0.05$ and $\mathrm{P}<0.01)$ in cell viability. Exposure of macrophages to these mycotoxins resulted in a dose-dependent modulation of cytokine secretion. Specifically, exposure to low doses of patulin (0.001, 0.1 and 1 $\mathrm{pg} / \mathrm{mL}$ ) resulted in a statistically significant decrease in the secretion of the pro-inflammatory cytokines interleukin (IL) 6 (IL-6) and tumor necrosis factor alpha (TNF- $\alpha$ ), following stimulation with lipopolysaccharide (LPS), a component of Gram-negative bacterial cell walls. Treatment with low doses of DON $(0.001 \mathrm{pg} / \mathrm{mL})$ and ZEN $(0.001$ and $0.01 \mathrm{pg} / \mathrm{mL})$ significantly decreased $(\mathrm{P}<0.01)$ the secretion of the pro-inflammatory cytokine IL-12p40, while several doses of T-2 toxin $(0.001,0.01,0.1,1$ and $100 \mathrm{pg} / \mathrm{mL})$ caused a significant decrease the expression of IL-6. Each of the mycotoxins also significantly increased the production of the anti-inflammatory cytokine IL-10, both before and after LPS stimulation. This data provides further insight into the mechanisms by which mycotoxins modulate the host immune response to exert their immunosuppressive activity.
\end{abstract}

Keywords: mycotoxins, macrophage, inflammation, immunosuppression, immunomodulation

\section{Introduction}

Mycotoxins are the naturally occurring toxic secondary metabolites of some fungal species. They are food contaminants which are proven to have detrimental effects on human and animal health. Their immunosuppressive and carcinogenic nature is of particular concern. The Food and Agriculture Organization (FAO) has estimated that $25 \%$ of the world's food supply is contaminated with mycotoxins (Marroquín-Cardona et al., 2015). Mycotoxin contamination can occur at any time during harvest or storage of food.

Over 400 different mycotoxins have been identified. They are structurally diverse (Figure 1) but are produced primarily by three genera of fungi: Aspergillus, Penicillium, and Fusarium. Patulin $(\sim 150 \mathrm{Da})$, a polyketide lactone is produced by Penicillium and Aspergillus. The trichothecenes $(\sim 250-550 \mathrm{Da})$ are a group of sesquiterpene epoxides produced mainly by Fusarium species while zearalenone $(\sim 318 \mathrm{Da})$ is a resorcyclic acid lactone also produced by Fusarium.

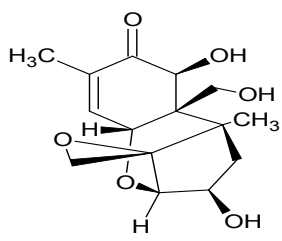

Deoxynivalenol (DON)

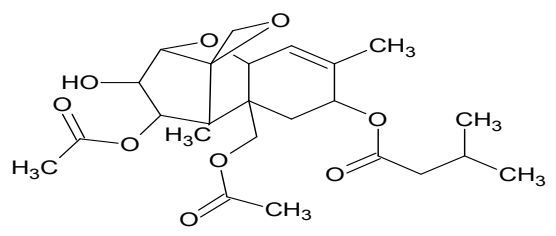

T-2 Toxin

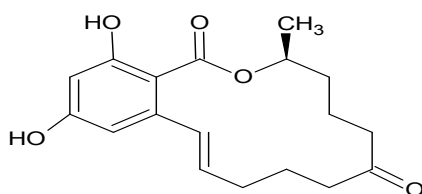

Zearalenone

(ZEN)

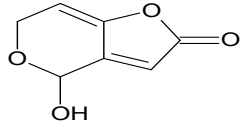

Patulin

Figure 1. Chemical structure of deoxynivalenol (DON), T-2 toxin, zearalenone (ZEN) and patulin. 
Mycotoxin contamination can occur in a variety of plants used as food, including commodities such as cereal grains (barley, corn, rye and wheat), coffee, dairy products, fruits, nuts, peanuts, and spices. Contamination can also arise in animal products, like milk, caused by animals consuming contaminated feeds. Generally, crops that are stored for more than a few days become a potential target for mold growth and mycotoxin formation. The primary way in which humans become exposed to mycotoxins is by eating contaminated food such as grain, corn, and other foodstuff or, alternatively, by consuming animals or animal products that have eaten contaminated feed. Mycotoxins are extremely stable compounds so they can easily avoid damage in the digestive system and reach the human bloodstream (Stoev, 2015).

Mycotoxins have the potential to elicit a wide variety of toxicological effects, including immune-suppression and immune-stimulation. Exposure to sublethal doses of many mycotoxins has the potential to either stimulate or suppress immune functions, such as lymphocyte proliferation, cell-mediated immunity and humoral immunity, depending on the dose and exposure time (Edite Bezerra da Rocha et al., 2014). Immunosuppression is viewed as one of the most significant effects of mycotoxin exposure and it has a major economic impact. Studies have already highlighted the immunosuppressive nature of several mycotoxins such as aflatoxins, trichothecenes, ochratoxin A and zearalenone (Ferrante et al., 2002; Sharma et al., 2004; Ferrante et al., 2008; Ubagai et al., 2008; Marzocco et al., 2009; Bianco et al., 2012; Bruneau et al., 2012; Alassane-Kpembi et al., 2013; Jia et al., 2014). Immunostimulation and immunosuppression can occur with the same toxin depending on the exposure conditions, including dosage and time. Such experimental observations have given rise to the term 'immunomodulation' which accounts for this dual effect. It is important to stress that any deregulation of immune cell homeostasis can result in serious consequences for immune functions, increasing susceptibility to infections and cancer, as well as favouring the development of autoimmune diseases. Therefore, any significant changes in the functionality of immune cells must be considered as a significant hazard (Marin et al., 2013).

Several studies have shown that the group of mycotoxins, aflatoxins, can affect macrophages, both in vitro and in vivo. Liu et al., (2002) showed that fumonisin B and aflatoxin B1 were immunotoxic to swine alveolar macrophages, employing techniques such as DNA laddering, nuclear fragmentation and phagocytosis, and by analysis of apoptosis-related heat shock protein 72 (hsp72) and cytokines IL-1 $\beta$ and TNF- $\alpha$. Numerous animal studies have demonstrated that aflatoxins have immunosuppressive activity. Poultry (chickens and turkeys), pigs and lambs in particular, are susceptible to aflatoxin-induced immunosuppression (Devegowda and Murthy, 2005). Furthermore, cell-mediated immunity is affected by aflatoxin exposure. Murine macrophages exposed to aflatoxins both in vivo and in vitro have exhibited decreased cytokine secretion. Other macrophage functions, such as release of reactive intermediates and phagocytosis are decreased in macrophages exposed to AFB1 (Liu et al., 2002). Although the immunomodulatory effects of the aflatoxins have been demonstrated previously, the mechanism by which these compounds exert their immunosuppressive effects is still unknown. Previous investigations have shown that AFB1 pretreatment, followed by LPS stimulation, decreases CD14 expression in murine peritoneal macrophages. However, CD14 expression was unaffected in cells that were pre-treated with AFB1, but not challenged with LPS (Moon and Pyo, 2000).

Mycotoxins can produce cellular depletion in lymphoid organs, cause alterations in T-cell and B-cell function, suppress antibody responses, suppress NK cell activity, decrease delayed-type hypersensitivity responses, and increase susceptibility to infectious disease. T-2 toxin was implicated as a developmental immunotoxicant, which targets fetal lymphocyte progenitors (Holladay et al., 2002). The effect of the trichothecenes group of mycotoxins on immune function has shown that the mechanism of impairment is related to inhibition of protein synthesis. High doses of trichothecenes induce lymphocyte apoptosis along with immune suppression. Low doses promote expression of cytokines including IL-1, IL-2, IL-5, and IL-6. Tricothecenes also activate mitogen-activated protein kinases (MAPK's) in vivo and in vitro, via the ribotoxic stress response (Zhou et al., 2003; Pestka et al., 2004). Pestka and Zhou (2006) shows that pre-exposure with LPS sensitises murine RAW264.7 macrophages and peritoneal murine macrophages to the pro-inflammatory effects of DON.

ZEN has been shown to be immunotoxic (Luongo et al., 2008) and has also been observed to be both a suppressor and inductor of the production of inflammatory cytokines (Salah-Abbès et al., 2008). Several alterations of immunological parameters were found associated with ZEN concentrations in vitro (Murata et al., 2003). Additive and synergistic effects of mycotoxins were demonstrated for various combinations of mycotoxins, such as ochrations, aflatoxins and ZEN, (Grenier and Oswald, 2011; Halbin et al., 2013; Lei et al., 2013). In vitro studies have shown that mycotoxin combinations can act additively, synergistically and even in some cases antagonistically (Bruneau et al., 2012; Clarke et al., 2014).

Macrophage activation by LPS results in expression of a number of pro-inflammatory cytokines, including IL-12p40, TNF- $\alpha$ and IL- 6 . This is then followed by the expression of anti-inflammatory cytokines, such as IL-10, to stop 
production of the pro-inflammatory cytokines and to ensure regulation of the immune response (Bruneau et al., 2012). Although these cytokines have important roles in host defence, their over- or under-expression can lead to problems such as inflammatory diseases. Since the macrophage is a key cell in the innate immune response, we investigated the effect of mycotoxins exposure on cell viability and cytokine secretion in a murine macrophage cell line, J774A.1. The aim of this study was to gain better understanding of the immunomodulatory effects of these compounds on macrophages, in order to shed light on their immunosuppressive activity.

\section{Materials and Methods}

\subsection{Reagents and Chemicals}

Patulin, deoxynivalenol, T-2 toxin, zearalenone and dimethyl sulphoxide (DMSO) were purchased from Sigma Aldrich (St. Louis, MO). Dulbecco's Modified Eagle's Medium (DMEM), Fetal Bovine Serum (FBS) and Penicillin/Streptomycin were purchased from Invitrogen (Carlsbad, CA). Lipopolysaccharide (LPS) isolated from $E$. coli, serotype R515, was purchased from Enzo Life Sciences (Farmingdale, NY). CellTiter $96^{\circledR}$ Aqueous One Solution was purchased from Thermo Fisher Scientific (Rockford, IL). DuoSet cytokine ELISA kits were purchased from R\&D Systems (Minneapolis, MN).

\subsection{Cell Culture}

The murine macrophage cell line J774A.1 was obtained from the European Collection of Cell Cultures (ECACC; Salisbury, UK). The cells were grown in DMEM supplemented with $10 \%(\mathrm{w} / \mathrm{v})$ fetal bovine serum, $50 \mathrm{U}$ penicillin and $50 \mu \mathrm{g}$ streptomycin. All cultures were maintained in a $37^{\circ} \mathrm{C}$, in $5 \% \mathrm{CO}_{2}$ humidified atmosphere. For cell viability analysis, $100 \mu \mathrm{L}$ of a J774A.1 cell suspension, at a concentration of $1 \times 10^{6}$ cells $/ \mathrm{mL}$, was added to each well of a NUNCTM96 well tissue culture plate and allowed to adhere for $1 \mathrm{~h}$. The cells were then incubated with the appropriate concentration of each mycotoxin for $24 \mathrm{~h} \pm 100 \mathrm{ng} / \mathrm{mL}$ LPS. The negative control consisted of cells incubated alone and with $0.1 \%(\mathrm{v} / \mathrm{v})$ methanol (vehicle). As a positive control, cells were incubated with $10 \% \mathrm{v} / \mathrm{v}$ DMSO. 24 hours after the addition of LPS, $20 \mu \mathrm{L}$ of the CellTiter 96® Aqueous One Solution was added to each well of the 96-well plate. The plates were incubated for 4 hours at $37^{\circ} \mathrm{C}$ in $5 \% \mathrm{CO}_{2}$ and absorbance read at $490 \mathrm{~nm}$. For cytokine expression analysis, $250 \mu \mathrm{L}$ of a J774A. 1 cell suspension, at a concentration of $1 \times 10^{6}$ cells $/ \mathrm{mL}$, was added to each well of a NUNCTM96 well tissue culture plate and allowed to adhere for $1 \mathrm{~h}$. The cells were then incubated with the appropriate concentration of each mycotoxin for $24 \mathrm{~h} \pm 100 \mathrm{ng} / \mathrm{mL}$ LPS to induce an inflammatory response. The negative control was made up of cells that were incubated alone and with $0.1 \%(\mathrm{v} / \mathrm{v})$ methanol (vehicle). At the end of the incubation time, the supernatant was removed and stored at $-20^{\circ} \mathrm{C}$ until analysis. All experiments were carried out in triplicate.

\subsection{Determination of Cell Viability}

The CellTiter $96^{\circledR}$ Aqueous One Solution (Pierce, UK) was employed for spectrophotometric quantification of cell viability. The assay was carried out according to the manufacturer's instructions. Percentage viability was calculated compared to untreated control cells. Each sample was assayed in triplicate.

\subsection{Cytokine ELISAS}

TNF- $\alpha$, IL-10, IL-6 and IL-12p40 ELISAs were performed according to the manufacturer's instructions (R\&D systems, UK). Each sample was assayed in triplicate for all of the cytokines indicated.

\subsection{Statistical Analysis}

Data was analyzed by ANOVA using Prism version 5 (GraphPad, La Jolla, CA, USA). If the ANOVA table was significant $(\mathrm{P}<0.05)$, Post-hoc analysis was performed using Dunnett's test.

\section{Results}

\subsection{ZEN and T-2 Toxin Affect J774A.1 Macrophage Cell Viability}

The viability of the J774A.1 murine macrophage cell line, in the presence of patulin, DON, ZEN and T-2 toxin in concentrations ranging from 10 to $100,000 \mathrm{pg} / \mathrm{mL}$, was assessed using the MTS assay. The inflammatory processes in the macrophage are activated by the endotoxin, LPS. Therefore, LPS was included in the MTS analysis, to determine the effect of toxin exposure on macrophage viability. The results indicate that patulin and DON have no cytotoxic effect on J774A.1 macrophages at any of the chosen concentrations. For ZEN there is a significant $(\mathrm{P}<0.05)$ decrease in the percentage viability at a concentration of $100,000 \mathrm{pg} / \mathrm{mL}$, which is cytotoxic without LPS stimulation (Figure 2). T-2 toxin shows a significant cytotoxic effect at $100,000 \mathrm{pg} / \mathrm{mL}(\mathrm{P}<0.01)$ for unstimulated cells and at $10,000 \mathrm{pg} / \mathrm{mL}(\mathrm{P}<$ $0.05)$ and $100,000 \mathrm{pg} / \mathrm{mL}(\mathrm{P}<0.01)$ for LPS-stimulated cells. All experiments show no effect of the vehicle control on cell viability with and without LPS stimulation. 

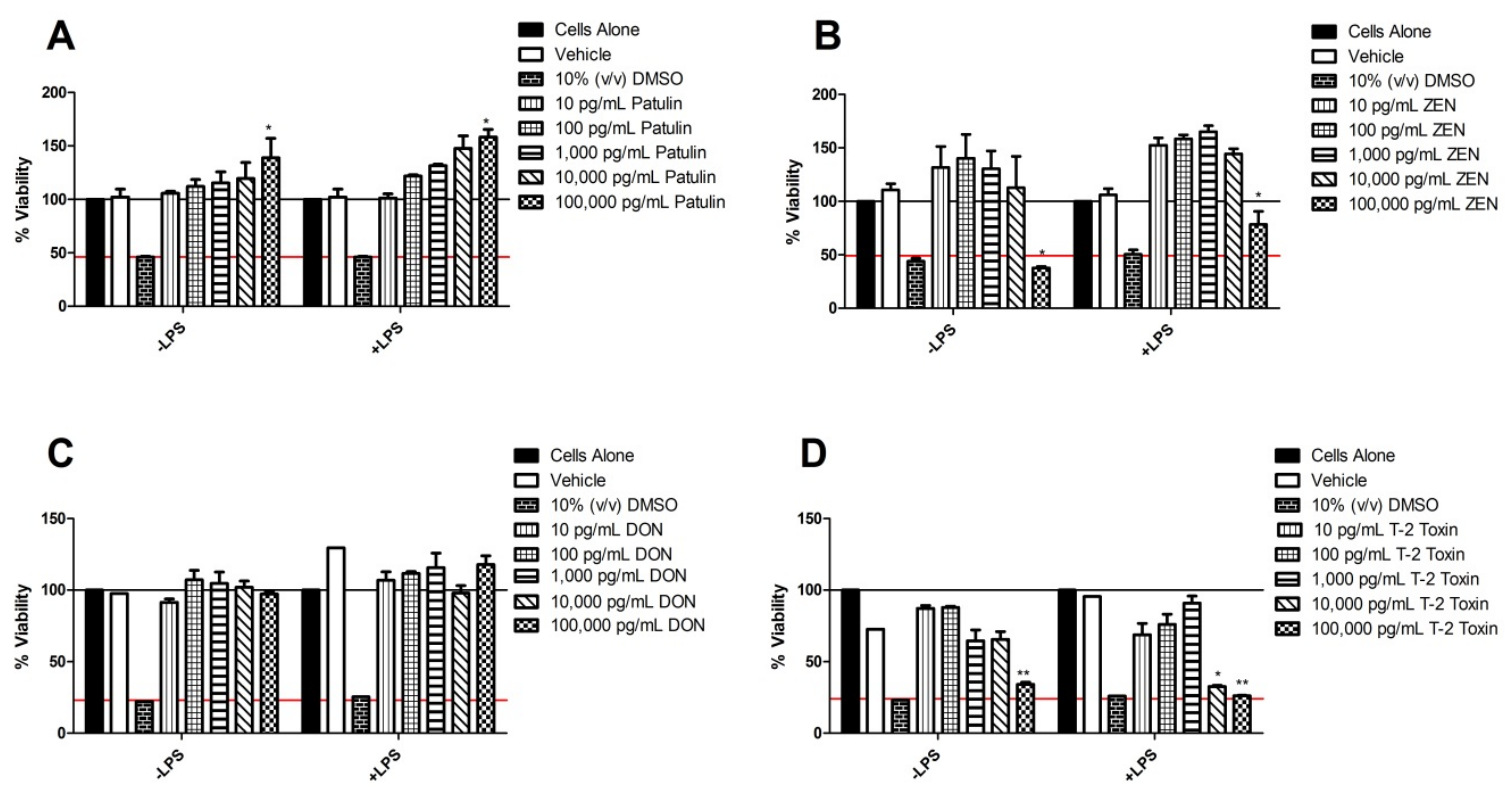

Figure 2. MTS proliferation assay to analyse the effect of patulin (A), ZEN (B), DON (C), and T-2 toxin (D) on the J774A.1 macrophage cell line.

J774A.1 cells were treated for 24 hours with each mycotoxin, ranging in concentration from 10 to $100,000 \mathrm{pg} / \mathrm{mL}$, with and without LPS $(100 \mathrm{ng} / \mathrm{mL})$ stimulation. DMSO $(10 \%, \mathrm{v} / \mathrm{v})$ was included as a positive control of cytotoxicity. Results indicate a mean value from three independent experiments and error bars represent mean $\pm 3 \mathrm{SE}$ (standard error of mean) $(\mathrm{n}=3)$. Significance: $\mathrm{P}<0.05^{*} ; \mathrm{P}<0.01^{* *} ; \mathrm{P}<0.001^{* * *}$ as illustrated, all relative to cells not exposed to toxin.

\subsection{Exposure of Macrophages to Single Mycotoxins Modulates Cytokine Secretion}

DuoSet ELISA kits (R\&D systems) were used to quantify the levels of cytokines (IL-6, IL-10, IL-12p40 and TNF- $\alpha$ ) in the supernatants of J774A.1 macrophage cells treated with patulin, DON, ZEN and T-2 toxin in increasing concentrations from 0.001 to $100 \mathrm{pg} / \mathrm{mL}$ for 24 hours with and without LPS $(100 \mathrm{ng} / \mathrm{mL})$ stimulation.

The results for patulin (Figure 3) (Table 1) show that there is a significant $(\mathrm{P}<0.001)$ increase in the expression of IL-6 at $10 \mathrm{pg} / \mathrm{mL}$ patulin without LPS stimulation, however, significant suppression is observed at $0.1 \mathrm{pg} / \mathrm{mL}(\mathrm{P}<0.01)$ and $1 \mathrm{pg} / \mathrm{mL}(\mathrm{P}<0.05)$. The production of IL-10 is increased significantly at $1 \mathrm{pg} / \mathrm{mL}(\mathrm{P}<0.01), 10 \mathrm{pg} / \mathrm{mL}(\mathrm{P}<0.001)$ and $100 \mathrm{pg} / \mathrm{mL}(\mathrm{P}<0.05)$ without LPS stimulation, and at $0.1-10 \mathrm{pg} / \mathrm{mL}(\mathrm{P}<0.01)$ following LPS treatment. An increase in IL-12p40 is observed at $10 \mathrm{pg} / \mathrm{mL}(\mathrm{P}<0.001)$ and $100 \mathrm{pg} / \mathrm{mL}(\mathrm{P}<0.01)$ without LPS stimulation and also $10 \mathrm{pg} / \mathrm{mL}$ and $100 \mathrm{pg} / \mathrm{mL}(\mathrm{P}<0.001)$ with LPS stimulation. TNF- $\alpha$ was increased at $10 \mathrm{pg} / \mathrm{mL}$ patulin $(-\mathrm{LPS})(\mathrm{P}<0.001)$ and (+LPS) $(\mathrm{P}<0.05)$, however, its levels were decreased at $0.001 \mathrm{pg} / \mathrm{mL}$ and $0.1 \mathrm{pg} / \mathrm{mL}(\mathrm{P}<0.05)$.

DON (Figure 4) (Table 2) causes a significant increase in IL-6 production at $1 \mathrm{pg} / \mathrm{mL}(\mathrm{P}<0.01)$ and $10 \mathrm{pg} / \mathrm{mL}(\mathrm{P}<$ $0.001)$ without LPS, and $10 \mathrm{pg} / \mathrm{mL}(\mathrm{P}<0.05)$ with LPS. Levels of IL-10 are increased significantly without LPS stimulation at $0.1 \mathrm{pg} / \mathrm{mL}(\mathrm{P}<0.01), 1 \mathrm{pg} / \mathrm{mL}(\mathrm{P}<0.001), 10 \mathrm{pg} / \mathrm{mL}(\mathrm{P}<0.001)$ and $100 \mathrm{pg} / \mathrm{mL}(\mathrm{P}<0.05)$ but only up for $10 \mathrm{pg} / \mathrm{mL}(\mathrm{P}<0.001)$ with LPS stimulation. IL-12p40 is significantly increased $(\mathrm{P}<0.001)$ at $10 \mathrm{pg} / \mathrm{mL} \mathrm{both}+$ and - LPS, while IL-12p40 is decreased $(\mathrm{P}<0.05)$ by $0.001 \mathrm{pg} / \mathrm{mL}$ DON following LPS stimulation. TNF- $\alpha$ is significantly increased at $0.1 \mathrm{pg} / \mathrm{mL}(\mathrm{P}<0.05), 1 \mathrm{pg} / \mathrm{mL}(\mathrm{P}<0.01)$ and $10 \mathrm{pg} / \mathrm{mL}(\mathrm{P}<0.001)$ without LPS, but only increased for 10 $\mathrm{pg} / \mathrm{mL}(\mathrm{P}<0.001)$ with LPS.

The results for ZEN (Figure 5) (Table 3) show that IL-6 is significantly increased $(\mathrm{P}<0.001) \mathrm{by} 0.1-100 \mathrm{pg} / \mathrm{mL} \mathrm{ZEN}$ with no LPS stimulation. However, no significant changed are observed for IL-6 following LPS treatment. IL-10 was significantly increased by $10 \mathrm{pg} / \mathrm{mL}(\mathrm{P}<0.001)$ before LPS treatment and by $0.01 \mathrm{pg} / \mathrm{mL}(\mathrm{P}<0.05), 0.1 \mathrm{pg} / \mathrm{mL}(\mathrm{P}<$ $0.01)$ and $1 \mathrm{pg} / \mathrm{mL}(\mathrm{P}<0.01)$ after LPS treatment. here is a significant increase in the levels of IL-12p40 at $10 \mathrm{pg} / \mathrm{mL}(\mathrm{P}$ $<0.001)$ (-LPS) but a significant decrease in its levels at 0.001 and $0.01 \mathrm{pg} / \mathrm{mL}(\mathrm{P}<0.01)(+\mathrm{LPS})$. TNF- $\alpha$ was significantly increased at $0.1 \mathrm{pg} / \mathrm{mL}(\mathrm{P}<0.05), 1 \mathrm{pg} / \mathrm{mL}(\mathrm{P}<0.05)$ and $10 \mathrm{pg} / \mathrm{mL}(\mathrm{P}<0.001)$ without LPS stimulation and $1 \mathrm{pg} / \mathrm{mL}(\mathrm{P}<0.05)$ and $10 \mathrm{pg} / \mathrm{mL}(\mathrm{P}<0.001)$ with LPS treatment. 
T-2 toxin (Figure 6) (Table 4) exposure resulted in a significant increase in IL-6 production at $0.1 \mathrm{pg} / \mathrm{mL}(\mathrm{P}<0.05) 1$ $\mathrm{pg} / \mathrm{mL}(\mathrm{P}<0.01)$ and $10 \mathrm{pg} / \mathrm{mL}(\mathrm{P}<0.001)$ (-LPS). However, significant suppression of IL-6 was observed at 0.001 $\mathrm{pg} / \mathrm{mL}(\mathrm{P}<0.001), 0.01 \mathrm{pg} / \mathrm{mL}(\mathrm{P}<0.001), 0.1 \mathrm{pg} / \mathrm{mL}(\mathrm{P}<0.01), 1 \mathrm{pg} / \mathrm{mL}(\mathrm{P}<0.05)$ and $100 \mathrm{pg} / \mathrm{mL}(\mathrm{P}<0.01)$ following LPS stimulation. IL-10 levels were increased $(\mathrm{P}<0.001)$ by $10 \mathrm{pg} / \mathrm{mL} \mathrm{T}-2$ without LPS but significant decrease was seen at $0.001 \mathrm{pg} / \mathrm{mL}(\mathrm{P}<0.05), 0.01 \mathrm{pg} / \mathrm{mL}(\mathrm{P}<0.001)$ and $100 \mathrm{pg} / \mathrm{mL}(\mathrm{P}<0.05)$. Following LPS stimulation an increase $(\mathrm{P}<0.01)$ of IL-10 was only seen at $10 \mathrm{pg} / \mathrm{mL}$ T-2 toxin. IL-12p40 levels were increased at 10 $\mathrm{pg} / \mathrm{mL}(\mathrm{P}<0.01)(-\mathrm{LPS})$, and $1 \mathrm{pg} / \mathrm{mL}(\mathrm{P}<0.05)$ and $10 \mathrm{pg} / \mathrm{mL}(\mathrm{P}<0.001)(+\mathrm{LPS})$. TNF- $\alpha$ production was significantly increased by $1 \mathrm{pg} / \mathrm{mL}(\mathrm{P}<0.05)$ and $10 \mathrm{pg} / \mathrm{mL}(\mathrm{P}<0.001)$, both with and without LPS stimulation. However, LPS stimulation also showed a significant decrease in TNF- $\alpha$ at $0.01 \mathrm{pg} / \mathrm{mL}(\mathrm{P}<0.05)$ and $1 \mathrm{pg} / \mathrm{mL}(\mathrm{P}<0.05) \mathrm{T}-2$ toxin.
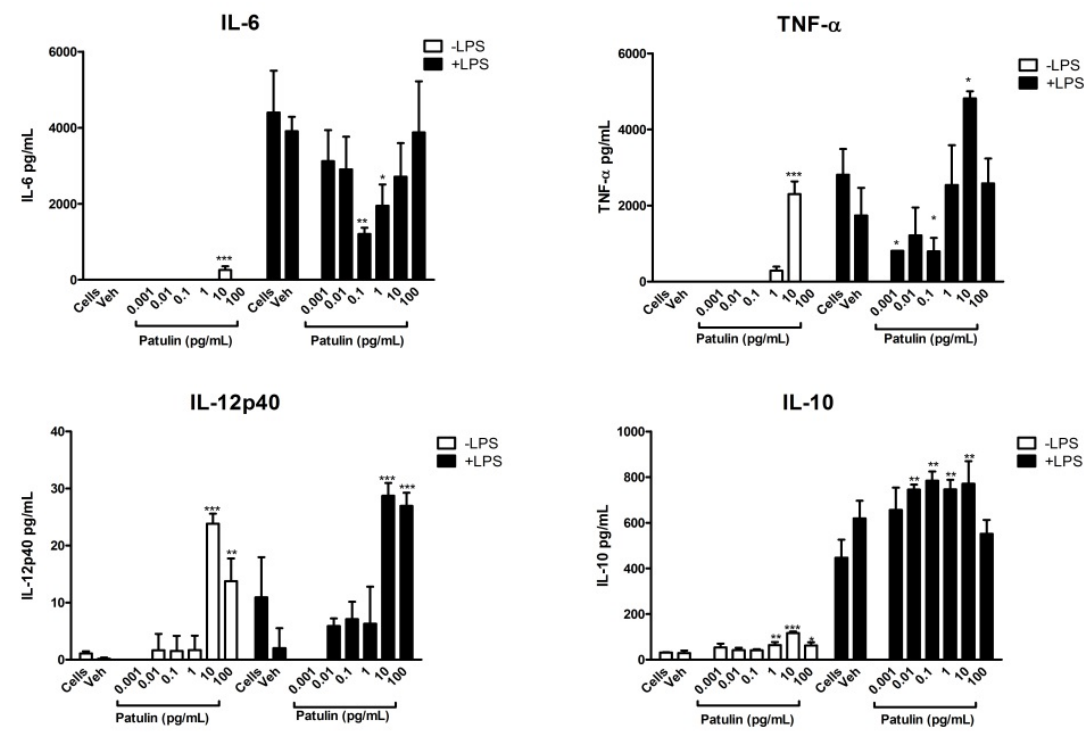

Figure 3. Expression of IL-6, IL-10, IL-12p40 and TNF- $\alpha$ in the supernatants of J774A.1 murine macrophage cells, cultured for 24 hours in the presence of patulin ranging in concentration from 0.001 to $100 \mathrm{pg} / \mathrm{mL}$, with and without LPS $(100 \mathrm{ng} / \mathrm{mL})$ stimulation.

The toxin treatment alone is represented by the white bars $(\square)$ and the toxin treatment with LPS challenge is represented by the black bars ( $\mathbf{m})$. Data was expressed as the mean for each experiment $(\mathrm{n}=3)$, with error bars indicating \pm 3 SE. Significance: $\mathrm{P}<0.05^{*} ; \mathrm{P}<0.01^{* *} ; \mathrm{P}<0.001^{* * *}$ as illustrated, all relative to cells not exposed to toxin.

Table 1. The effect of increasing concentrations of patulin $(0.001-100 \mathrm{pg} / \mathrm{mL})$ on the expression levels of cytokines from J774A.1 macrophages with and without LPS $(100 \mathrm{ng} / \mathrm{mL})$ treatment. Significance represented by: no change -, increase $\mathrm{P}<0.05 \uparrow ; \mathrm{P}<0.01 \uparrow \uparrow ; \mathrm{P}<0.001 \uparrow \uparrow$, decrease $\mathrm{P}<0.05 \downarrow ; \mathrm{P}<0.01 \downarrow \downarrow ; \mathrm{P}<0.001 \downarrow \downarrow \downarrow$, compared to control cells.

\begin{tabular}{lllll}
\hline Patulin (pg/mL) & IL-6 & IL-10 & IL-12p40 & TNF- $\boldsymbol{~}$ \\
\hline $\mathbf{0 . 0 0 1}$ & - & - & - & - \\
$\mathbf{0 . 0 1}$ & - & - & - & - \\
$\mathbf{0 . 1}$ & - & - & - & - \\
$\mathbf{1}$ & - & $\uparrow \uparrow$ & - & - \\
$\mathbf{1 0}$ & $\uparrow \uparrow \uparrow$ & $\uparrow \uparrow \uparrow$ & $\uparrow \uparrow \uparrow$ & $\uparrow \uparrow \uparrow$ \\
$\mathbf{1 0 0}$ & - & $\uparrow$ & $\uparrow \uparrow$ & - \\
\hline Patulin (pg/mL) & & & & \\
$+\mathbf{L P S}(\mathbf{1 0 0} \mathbf{n g} / \mathbf{m L})$ & & & & \\
\hline $\mathbf{0 . 0 0 1}$ & - & - & - & $\downarrow$ \\
$\mathbf{0 . 0 1}$ & - & $\uparrow \uparrow$ & - & - \\
$\mathbf{0 . 1}$ & $\downarrow \downarrow$ & $\uparrow \uparrow$ & - & $\downarrow$ \\
$\mathbf{1}$ & $\downarrow$ & $\uparrow \uparrow$ & - & - \\
$\mathbf{1 0}$ & - & $\uparrow \uparrow$ & $\uparrow \uparrow \uparrow$ & $\uparrow$ \\
$\mathbf{1 0 0}$ & - & - & $\uparrow \uparrow \uparrow$ & - \\
\hline
\end{tabular}



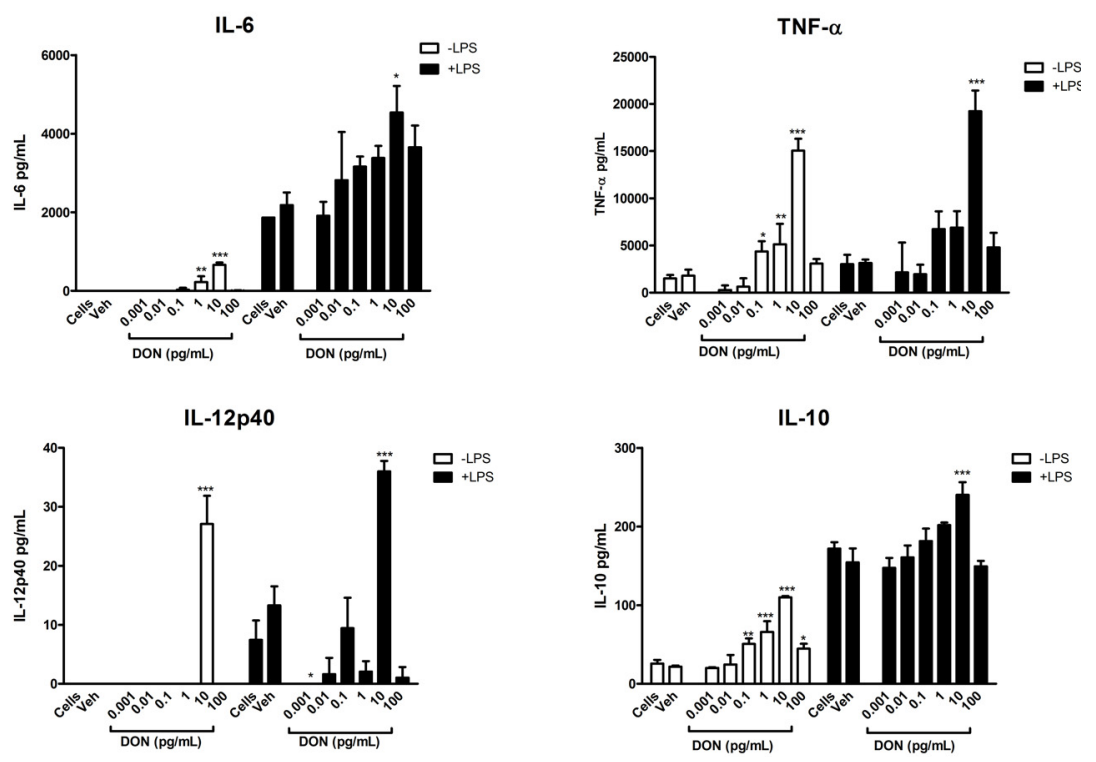

Figure 4. Expression of IL-6, IL-10, IL-12p40 and TNF- $\alpha$ in the supernatants of J774A.1 murine macrophage cells, cultured for 24 hours in the presence of DON ranging in concentration from 0.001 to $100 \mathrm{pg} / \mathrm{mL}$, with and without LPS $(100 \mathrm{ng} / \mathrm{mL})$ stimulation.

The toxin treatment alone is represented by the white bars $(\square)$ and the toxin treatment with LPS challenge is represented by the black bars $(\mathbf{m})$. Data was expressed as the mean for each experiment $(\mathrm{n}=3)$, with error bars indicating \pm 3 SE. Significance: $\mathrm{P}<0.05^{*} ; \mathrm{P}<0.01^{* *} ; \mathrm{P}<0.001^{* * *}$ as illustrated, all relative to cells not exposed to toxin.

Table 2. The effect of increasing concentrations of DON $(0.001-100 \mathrm{pg} / \mathrm{mL})$ on the expression levels of cytokine from J774A.1 macrophages with and without LPS $(100 \mathrm{ng} / \mathrm{mL})$ treatment. Significance represented by: no change -, increase $\mathrm{P}<0.05 \uparrow ; \mathrm{P}<0.01 \uparrow \uparrow ; \mathrm{P}<0.001 \uparrow \uparrow$, decrease $\mathrm{P}<0.05 \downarrow ; \mathrm{P}<0.01 \downarrow \downarrow ; \mathrm{P}<0.001 \downarrow \downarrow \downarrow$, compared to control cells.

\begin{tabular}{|c|c|c|c|c|}
\hline DON $(\mathrm{pg} / \mathrm{mL})$ & IL-6 & IL-10 & IL-12p40 & TNF-o \\
\hline 0.001 & - & - & - & - \\
\hline 0.01 & - & - & - & - \\
\hline 0.1 & - & 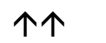 & - & $\uparrow$ \\
\hline 1 & 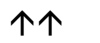 & 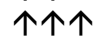 & - & 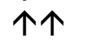 \\
\hline 10 & 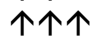 & 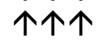 & 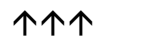 & 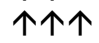 \\
\hline 100 & - & & & - \\
\hline \multicolumn{5}{|c|}{$\begin{array}{l}\text { DON }(\mathrm{pg} / \mathrm{mL}) \\
+ \text { LPS }(100 \mathrm{ng} / \mathrm{mL})\end{array}$} \\
\hline 0.001 & - & - & $\downarrow$ & - \\
\hline 0.01 & - & - & - & - \\
\hline 0.1 & - & - & - & - \\
\hline 1 & - & - & - & - \\
\hline 10 & $\uparrow$ & 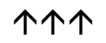 & 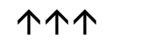 & 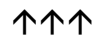 \\
\hline 100 & - & - & - & \\
\hline
\end{tabular}



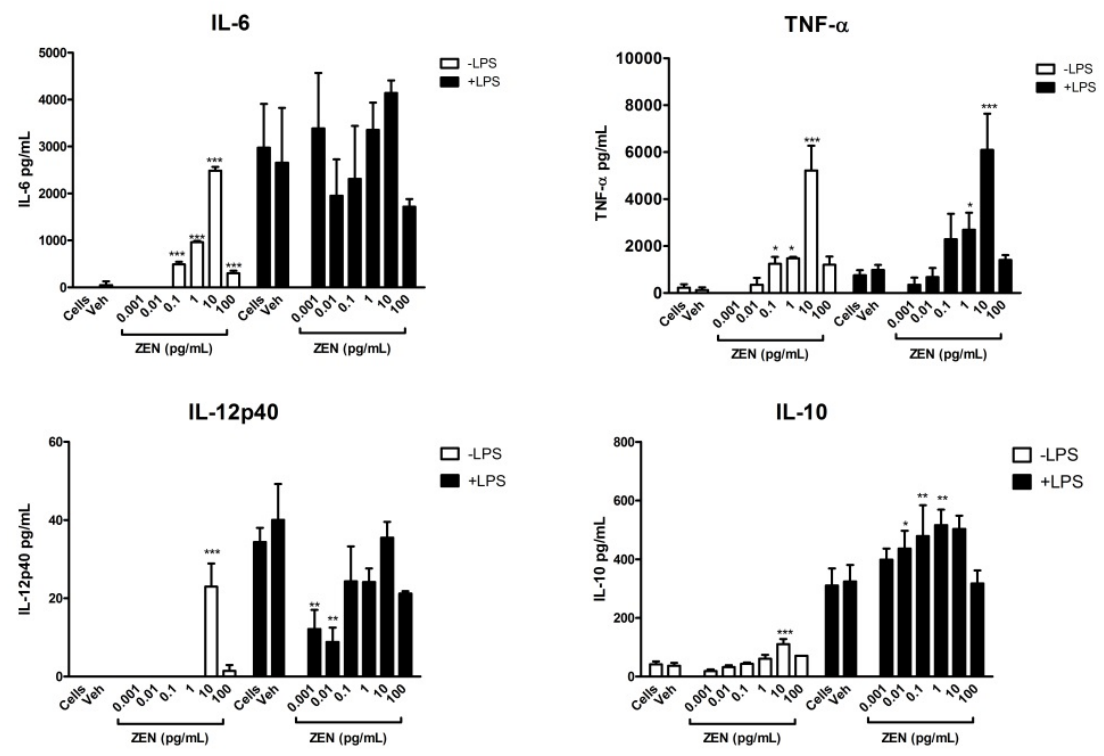

Figure 5. Expression of IL-6, IL-10, IL-12p40 and TNF- $\alpha$ in the supernatants of J774A.1 murine macrophage cells, cultured for 24 hours in the presence of ZEN ranging in concentration from 0.001 to $100 \mathrm{pg} / \mathrm{mL}$, with and without LPS $(100 \mathrm{ng} / \mathrm{mL})$ stimulation.

The toxin treatment alone is represented by the white bars $(\square)$ and the toxin treatment with LPS challenge is represented by the black bars ( $\mathbf{\square})$. Data was expressed as the mean for each experiment $(n=3)$, with error bars indicating \pm 3 SE. Significance: $\mathrm{P}<0.05^{*} ; \mathrm{P}<0.01 * * ; \mathrm{P}<0.001^{* * *}$ as illustrated, all relative to cells not exposed to toxin.

Table 3. The effect of increasing concentrations of ZEN $(0.001-100 \mathrm{pg} / \mathrm{mL})$ on the expression levels of cytokines from J774A.1 macrophages with and without LPS $(100 \mathrm{ng} / \mathrm{mL})$ treatment. Significance represented by: no change -, increase $\mathrm{P}<0.05 \uparrow ; \mathrm{P}<0.01 \uparrow \uparrow ; \mathrm{P}<0.001 \uparrow \uparrow$, decrease $\mathrm{P}<0.05 \downarrow ; \mathrm{P}<0.01 \downarrow \downarrow ; \mathrm{P}<0.001 \downarrow \downarrow \downarrow$, compared to control cells.

\begin{tabular}{|c|c|c|c|c|}
\hline ZEN (pg/mL) & IL-6 & IL-10 & IL-12p40 & TNF- $\alpha$ \\
\hline 0.001 & - & - & - & - \\
\hline 0.01 & - & - & - & - \\
\hline 0.1 & 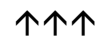 & - & - & $\uparrow$ \\
\hline 1 & 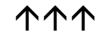 & - & - & 个 \\
\hline 10 & 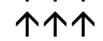 & 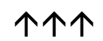 & 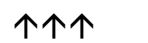 & 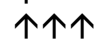 \\
\hline 100 & 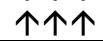 & - & - & - \\
\hline \multicolumn{5}{|c|}{$\begin{array}{l}\text { ZEN (pg/mL) } \\
+ \text { LPS }(100 \mathrm{ng} / \mathrm{mL})\end{array}$} \\
\hline 0.001 & - & - & - & - \\
\hline 0.01 & - & $\uparrow$ & $\downarrow \downarrow$ & - \\
\hline 0.1 & - & 个个 & $\downarrow \downarrow$ & - \\
\hline 1 & - & 个个 & - & $\uparrow$ \\
\hline 10 & - & - & - & 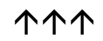 \\
\hline 100 & - & - & - & - \\
\hline
\end{tabular}



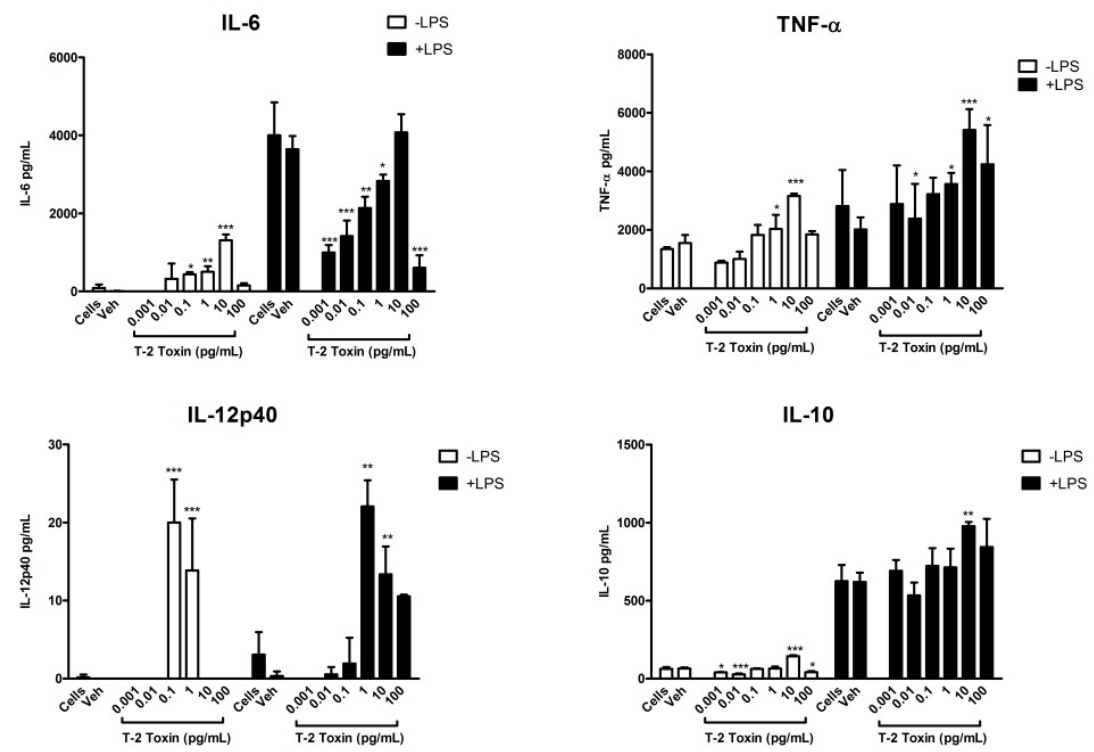

Figure 6. Expression of IL-6, IL-10, IL-12p40, and TNF- $\alpha$ in the supernatants of J774A.1 murine macrophage cells, cultured for 24 hours in the presence of T-2 toxin ranging in concentration from 0.001 to $100 \mathrm{pg} / \mathrm{mL}$, with and without LPS (100 ng/mL) stimulation.

The toxin treatment alone is represented by the white bars $(\square)$ and the toxin treatment with LPS challenge is represented by the black bars ( $\square)$. Data was expressed as the mean for each experiment $(n=3)$, with error bars indicating \pm 3 SE. Significance: $\mathrm{P}<0.05^{*} ; \mathrm{P}<0.01^{* *} ; \mathrm{P}<0.001^{* * *}$ as illustrated, all relative to cells not exposed to toxin.

Table 4. The effect of increasing concentrations of T-2 toxin $(0.001-100 \mathrm{pg} / \mathrm{mL})$ on the expression levels of cytokines from J774A.1 macrophages with and without LPS $(100 \mathrm{ng} / \mathrm{mL})$ treatment. Significance represented by: no change -, increase $\mathrm{P}<0.05 \uparrow ; \mathrm{P}<0.01 \uparrow \uparrow ; \mathrm{P}<0.001 \uparrow \uparrow$, decrease $\mathrm{P}<0.05 \downarrow ; \mathrm{P}<0.01 \downarrow \downarrow ; \mathrm{P}<0.001 \downarrow \downarrow \downarrow$, compared to control cells.

\section{Discussion}

\begin{tabular}{lllll}
\hline T-2 toxin (pg/mL) & IL-6 & IL-10 & IL-12p40 & TNF- $\alpha$ \\
\hline $\mathbf{0 . 0 0 1}$ & - & $\downarrow$ & - & - \\
$\mathbf{0 . 0 1}$ & - & $\downarrow \downarrow \downarrow$ & - & - \\
$\mathbf{0 . 1}$ & $\uparrow$ & - & - & - \\
$\mathbf{1}$ & $\uparrow \uparrow$ & - & - & $\uparrow$ \\
$\mathbf{1 0}$ & $\uparrow \uparrow \uparrow$ & $\uparrow \uparrow \uparrow$ & $\uparrow \uparrow$ & $\uparrow \uparrow$ \\
$\mathbf{1 0 0}$ & - & $\downarrow$ & - & - \\
\hline T-2 toxin (pg/mL) & & & & \\
$+\mathbf{L P S}(\mathbf{1 0 0} \mathbf{n g} / \mathbf{m L})$ & & - & - & $\downarrow$ \\
\hline $\mathbf{0 . 0 0 1}$ & $\downarrow \downarrow \downarrow$ & - & - & $\downarrow$ \\
$\mathbf{0 . 0 1}$ & $\downarrow \downarrow \downarrow$ & - & - & - \\
$\mathbf{0 . 1}$ & $\downarrow \downarrow$ & - & $\uparrow$ & $\uparrow$ \\
$\mathbf{1}$ & $\downarrow$ & - & $\uparrow \uparrow \uparrow$ & $\uparrow \uparrow \uparrow$ \\
$\mathbf{1 0}$ & $-\uparrow \uparrow$ & - & $\uparrow$ \\
$\mathbf{1 0 0}$ & - & - & & \\
\hline
\end{tabular}

Under normal healthy conditions, the immune system defends the host against pathogenic infections. However, certain environmental factors, including toxins, can alter the development and function of the immune response, leading to autoimmunity, hypersensitivity or immunosuppression. The understanding of the biological processes underlying immune system dysfunction by mycotoxins is incomplete.

Mycotoxin contamination is widespread and exposure to low levels of the toxins is unavoidable, therefore it is imperative to understand the effect of exposure to low doses. The effects of various mycotoxins on the immune system has been widely investigated (Sharma et al., 2004; Ferrante et al., 2008; Ubagai et al., 2008; Marzocco et al., 2009; 
Bianco et al., 2012; Alassane-Kpembi et al., 2013; Clarke et al., 2014; Solhaug et al., 2015), but there is a lack of understanding of the exact mechanisms behind the interactions involved. The effects of individual toxins can vary depending on concentration, time and other environmental factors.

The aim of this study was to characterise the individual effects of patulin, DON, ZEN and T-2 toxin in order to improve understanding of the individual molecular mechanisms of mycotoxin immunomodulation.

The effect that each of these mycotoxins has on the viability of J774A.1 murine macrophages was examined. The result of this investigation showed that patulin and DON did not display cytotoxic effects on the macrophage cells at any of the chosen concentrations. In contrast, ZEN has a significant $(\mathrm{P}<0.05)$ effect on cell viability at $100,000 \mathrm{pg} / \mathrm{mL}$ and is cytotoxic without LPS stimulation at this concentration. T-2 toxin becomes significantly cytotoxic $(\mathrm{P}<0.01)$ at 10,000 and $100,000 \mathrm{pg} / \mathrm{mL}$.

Other studies have demonstrated the cytotoxic nature of mycotoxins. Clarke et al. (2014) examined the cytotoxicity of AFB1, fumonisin B1 (FB1) and ochratoxin A (OTA) on Caco-2, MDBK and RAW264.7 cell lines. They also found these toxins to be cytotoxic, but at much higher concentrations to that used in this study. Hymery et al. (2014) found that the mycotoxin cyclopiazonic acid was toxic to the human cell lines; CD34+, monocytes, THP-1 and Caco-2. Notably, Marzocco et al. (2009)\#showed that both nivalenol (NIV) and DON (10-100 $\mu \mathrm{M})$ significantly stimulate apoptosis in J774A.1 macrophages in a concentration-dependent manner on cultured J774A.1 murine macrophages. Capasso et al. (2015) demonstrated that low doses of DON used alone have minor toxic effects, while induce cytotoxicity and inflammation when used in combination with particulate matter.\#Ferrante et al. (2008) showed that OTA $(30 \mathrm{nM}-100 \mu \mathrm{M})$ induces a time and concentration dependent cytotoxic effect on J774A.1 macrophages, increased when cells were co-stimulated with LPS $(100 \mathrm{ng} / \mathrm{mL})$, a concentration that alone did not modify the cellular viability.\#

Mycotoxins may not be cytotoxic at low concentrations but this does not mean they are not causing dysfunction to the immune system. The cytokine expression analysis presented here, clearly shows that these mycotoxins have varying effects on the expression of IL-6, IL-10, IL-12p40 and TNF- $\alpha$, which are dependent on toxin dosage and exposure to LPS stimulation. Depending on the dosage, it is possible for mycotoxins to be immunostimulatory as well as immunosuppressive.

Exposure of macrophages to patulin, DON, ZEN and T-2 toxin resulted in a dose-dependent modulation of cytokine secretion. For example, a significant increase in pro-inflammatory cytokines was observed in cells that were exposed to high concentrations $(10 \mathrm{pg} / \mathrm{mL})$ of the mycotoxins without LPS treatment. This pro-inflammatory response can also be seen for each toxin at the $10 \mathrm{pg} / \mathrm{mL}$ concentration after LPS treatment, with statistically significant increases in the secretion of IL-6, IL-12p40 and TNF- $\alpha$. DON also demonstrates a potent pro-inflammatory response overall at 10 $\mathrm{pg} / \mathrm{mL}$ both with and without LPS stimulation. Exposure to low doses of patulin resulted in a statistically significant decrease in the secretion of IL- 6 and TNF- $\alpha$ following stimulation with LPS. Treatment with low doses of DON and ZEN significantly decreased the secretion of IL-12p40, while nearly all doses of T-2 toxin caused a significant decrease the expression of IL-6.

There are very few published reports on the effect of mycotoxins on immune regulation, particularly cytokine secretion. Ferrante et al. (2008) observed that OTA $(3 \mu \mathrm{M})$ alone induces a significant increase in cyclooxygenase-2 (COX-2) and inducible nitric oxide synthase (iNOS) expression, while at the highest concentration $(10 \mu \mathrm{M})$ a reduced expression of both enzymes was shown. When cells were co-stimulated with LPS, OTA showed a concentration-dependent reduction of COX-2 and iNOS expression. These results confirm the pro-inflammatory role of OTA by itself, and demonstrate the impaired capability of OTA-treated macrophages to respond properly to noxious stimuli, such as LPS, mimicking the environmental co-exposure to both compounds. Bruneau et al. (2012) investigated the effect of AFB1, AFB2 and AFG1 exposure, alone and in combination, on the secretion of key pro- and anti-inflammatory cytokines from the murine macrophage cell line, J774A.1. Exposure of macrophages to low doses of aflatoxin $(0.01 \mathrm{or} 0.1 \mathrm{ng} / \mathrm{mL})$ resulted in a statistically significant change in the secretion of a number of cytokines following stimulation with LPS. Treatment with AFB1 or AFB2 alone significantly decreased the secretion of IL-10, while the secretion of the pro-inflammatory cytokine IL-6 was significantly increased. The study also demonstrated how aflatoxin exposure affects expression levels of key cell surface markers involved in the inflammatory response. TLR2 and CD14 expression levels decreased significantly, TLR4 expression was unaffected. Jia et al. (2014) showed that ZEN increased mRNA and protein expression of TLR4 and inflammatory cytokines in kidney in dose-dependent manner. Their results indicated that TLR4-mediated inflammatory reactions signal pathway was one of the mechanisms of ZEN-mediated toxicity in the kidney.

\section{Conclusion}

In conclusion, the results from this investigation demonstrate that although these compounds come from similar sources, due to the differences in structure, they exert variable effects on cytokine production. Overall, the results indicate that 
individually patulin, DON, ZEN and T-2 toxin have the ability to modulate the typical inflammatory response of macrophages to LPS stimulus. In particular, these toxins affected the secretion of cytokines that are critical for the normal host responses to infection. This is the first report on the effect of patulin, DON, ZEN and T-2 toxin on the modulation of these important pro- and anti-inflammatory cytokines. From this research, it is clear that these mycotoxins have the ability to cause macrophage dysfunction. Some of the molecular processes of toxicity are still not fully understood. However, this report has provided data on the potential mechanisms by which mycotoxins inhibit macrophage functions and, therefore, host defence functions, through deregulation of cytokine profiles.

\section{Acknowledgments}

This project is funded by the Irish Research Council and Science Foundation Ireland.

\section{References}

Alassane-Kpembi, I., Kolf-Clauw, M., Gauthier, T., Abrami, R., Abiola, F. A., Oswald, I. P., \& Puel, O. (2013). New insights into mycotoxin mixtures: The toxicity of low doses of type B trichothecenes on intestinal epithelial cells is synergistic. Toxicol. Appl. Pharmacol., 272(1), 191-198. http://dx.doi.org/10.1016/j.taap.2013.05.023.

Bianco, G., Russo, R., Marzocco, S., Velotto, S., Autore, G., \& Severino, L. (2012). Modulation of macrophage activity by aflatoxins B1 and B2 and their metabolites aflatoxins M1 and M2. Toxicon., 59(6), 644-650. http://dx.doi.org/10.1016/j.toxicon.2012.02.010.

Bruneau, J. C., Stack, E., O'Kennedy, R., \& Loscher, C. E. (2012). Aflatoxins B1, B2 and G1 modulate cytokine secretion and cell surface marker expression in J774A.1 murine macrophages. Toxicol. In Vitro., 26(5), 686-693. http://dx.doi.org/10.1016/j.tiv.2012.03.003.

Capasso, L., Longhin, E., Caloni, F., Camatini, M., \& Gualtieri, M. (2015). Synergistic inflammatory effect of PM10 with mycotoxin deoxynivalenol on human lung epithelial cells. Toxicon., 104, 65-72. http://dx.doi.org/10.1016/j.toxicon.2015.08.008.

Clarke, R., Connolly, L., Frizzell, C., \& Elliott, C. T. (2014). Cytotoxic assessment of the regulated, co-existing mycotoxins aflatoxin B1, fumonisin B1 and ochratoxin, in single, binary and tertiary mixtures. Toxicon., 90, 70-81. http://dx.doi.org/10.1016/j.toxicon.2014.07.019.

Devegowda, G., \& Murthy, T. K. N. (2005). Mycotoxins: their adverse effects in poultry and some practical solutions. In The Mycotoxin Blue Book, 1st Edition. Editors, Diaz, D. E. Nottingham University Press, Nottingham, UK, $25-26$

Edite Bezerra da Rocha, M., Freire, F. D. C. O., Erlan, F. M. F., Izabel, F. G. M., \& Rondina, D. (2014). Mycotoxins and their effects on human and animal health. Food Control., 36(1), 159-165. http://dx.doi.org/10.1016/j.foodcont.2013.08.021.

Ferrante, M. C., Meli, R., Raso, G. M., Esposito, E., Severino, L., Di Carlo, G., \& Lucisano, A. (2002). Effect of fumonisin B on structure and function of macrophage plasma membrane. Toxicol. Lett., 129(3), 181-187. http://dx.doi.org/10.1016/S0378-4274(01)00476-3.

Ferrante, M. C., Raso, M. G., Bilancione, M., Esposito, E., Iacono, A., \& Meli, R. (2008). Differential modification of inflammatory enzymes in J774A.1 macrophages by ochratoxin a alone or in combination with lipopolysaccharide. Toxicol. Lett., 181(1), 40-46. http://dx.doi.org/10.1016/j.toxlet.2008.06.866.

Grenier, B., \& Oswald, I. (2011). Mycotoxin co-contamination of food and feed: meta-analysis of publications describing toxicological interactions. World Mycotoxin J., 4, 285-313. http://dx.doi.org/10.3920/wmj2011.1281.

Halbin, K. J., Kouakou, B., \& Dago, G. (2013). Low level of ochratoxin A enhances aflatoxin B1 induced cytotoxicity and lipid peroxidation in both human intestinal (caco-2) and hepatoma (HepG2) cell lines. J. Nutr. Food Sci., 2(6), 294-30. http://dx.doi.org/10.11648/j.ijnfs.20130206.15.

Holladay, S. D., \& Blaylock, B. L. (2002). The mouse as a model for developmental immunotoxicology. Hum. Exp. Toxicol., 9-10, 525-531. http://dx.doi.org/10.1191/0960327102ht292oa.

Hymery, N., Masson, F., Barbier, G., \& Coton, E. (2014). Cytotoxicity and immunotoxicity of cyclopiazonic acid on human cells. Toxicol. In Vitro., 28(5), 940-947. http://dx.doi.org/10.1016/j.tiv.2014.04.003.

Jia, Z., Liu, M., Qu, Z., Zhang, Y., Yin, S., \& Shan, A. (2014). Toxic effects of zearalenone on oxidative stress, inflammatory cytokines, biochemical and pathological changes induced by this toxin in the kidney of pregnant rats. Environ. Toxicol. Pharmacol., 37(2), 580-591. http://dx.doi.org/10.1016/j.etap.2014.01.010.

Lei, M., Zhang, N., \& Desheng, Q. (2013). In vitro investigation of individual and combined cytotoxic effects of 
aflatoxin B1 and other selected mycotoxins on the cell line porcine kidney 15. Exp. Toxicol. Pathol., 63, 1149-1157. http://dx.doi.org/10.1016/j.etp.2013.05.007.

Liu, B., Yu, F., Chan, M., \& Yang, Y. (2002). The effects of mycotoxins, fumonisin B1 and aflatoxin B1, on primary swine alveolar macrophages. Toxicol. Appl. Pharmacol., 3, 197-204. http://dx.doi.org/10.1006/taap.2002.9406.

Luongo, D., Severino, L., Bergamo, P., De Luna, R., Lucisano, A., \& Rossi, M. (2006). Interactive effects of fumonisin $\mathrm{B} 1$ and alpha-zearalenol on proliferation and cytokine expression in Jurkat T cells. Toxicol. In. Vitro., 8, 1403-1410. http://dx.doi.org/10.1016/j.tiv.2006.06.006.

Marin, S., Ramos, A. J., Cano-Sancho, G., \& Sanchis, V. (2013). Mycotoxins: Occurrence, toxicology, and exposure assessment. Food Chem. Toxicol., 60, 218-237. http://dx.doi.org/10.1016/j.fct.2013.07.047.

Marroquín-Cardona, A. G., Johnson, N. M., Phillips, T. D., \& Hayes, A. W. (2014). Mycotoxins in a changing global environment - A review. Food and Chem. Toxicol., 69, 220-230. http://dx.doi.org/10.1016/j.fct.2014.04.025.

Marzocco, S., Russo, R., Bianco, G., Autore, G., \& Severino, L. (2009). Pro-apoptotic effects of nivalenol and deoxynivalenol trichothecenes in J774A.1 murine macrophages. Toxicol. Lett., 189(1), 21-26. http://dx.doi.org/10.1016/j.toxlet.2009.04.024.

Moon, E. Y., \& Pyo, S. (2000). Aflatoxin B1 inhibits CD14-mediated nitric oxide production in murine peritoneal macrophages. Int. J. Immunopharmacol., 3, 237-246. http://dx.doi.org/10.1016/S0192-0561(99)00081-8.

Mosser, D. M., \& Edwards, J. P. (2008). Exploring the full spectrum of macrophage activation. Nat. Rev. Immunol., 8 , 958-969. http://dx.doi.org/10.1038/nri2788.

Murata, H., Sultana, P., Shimada, N., \& Yashioka, M. (2003). Structure-activity relationships among zearalenone and its derivatives based on bovine neutrophil chemiluminescence. Vet. Hum. Toxicol., 45(1), 18-20.

Pestka, J. J., \& Zhou, H. R. (2006). Toll-like receptor priming sensitizes macrophages to proinflammatory cytokine gene induction by deoxynivalenol and other toxicants. Toxicol. Sci., 2, 445-455. http://dx.doi.org/10.1093/toxsci/kfl012.

Pestka, J. J., Zhou, H. R., Moon, Y., \& Chung, Y. J. (2004). Cellular and molecular mechanisms for immune modulation by deoxynivalenol and other trichothecenes: unraveling a paradox. Toxicol. Lett., 1, 61-73. http://dx.doi.org/10.1016/j.toxlet.2004.04.023.

Salah-Abbès, B., Abbès S., Houas, Z., Abdel-Wahhab, M. A., \& Oueslati, R. (2008). Zearalenone induces immunotoxicity in mice: possible protective effects of radish extract (Raphanus sativus). J. Pharm. Pharmacol., 60, 761-70. http://dx.doi.org/10.1211/jpp.60.6.0012.

Sharma, N., He, Q., \& Sharma, R. P. (2004). Augmented fumonisin B toxicity in co-cultures: Evidence for crosstalk between macrophages and non-parenchymatous liver epithelial cells involving proinflammatory cytokines. Toxicol., 203(1-3), 239-251. http://dx.doi.org/10.1016/j.tox.2004.06.017.

Solhaug, A., Wisbech, C., Christoffersen, T. E., Hult, L. O., Lea, T., Eriksen, G. S., \& Holme, J. A. (2015). The mycotoxin alternariol induces DNA damage and modify macrophage phenotype and inflammatory responses. Toxicol. Lett., 239(1), 9-21. http://dx.doi.org/10.1016/j.toxlet.2015.08.1107.

Stoev, S. D. (2015). Foodborne mycotoxicoses, risk assessment and underestimated hazard of masked mycotoxins and joint mycotoxin effects or interaction. Environ. Toxicol. Pharmacol., 39(2), 794-809. http://dx.doi.org/10.1016/j.etap.2015.01.022.

Ubagai, T., Tansho, S., Ito, T., \& Ono, Y. (2008). Influences of aflatoxin B1 on reactive oxygen species generation and chemotaxis of human polymorphonuclear leukocytes. Toxicol. In Vitro., 4, 1115-1120. http://dx.doi.org/10.1016/j.tiv.2008.01.007.

Zhou, H. R., Islam, Z., \& Pestka, J. J. (2003). Rapid, sequential activation of mitogenactivated protein kinases and transcription factors precedes proinflammatory cytokine mRNA expression in spleens of mice exposed to the trichothecene vomitoxin. Toxicol. Sci., 1, 130-142. http://dx.doi.org/10.1093/toxsci/kfg006.

\section{Copyrights}

Copyright for this article is retained by the author(s), with first publication rights granted to the journal.

This is an open-access article distributed under the terms and conditions of the Creative Commons Attribution license (http://creativecommons.org/licenses/by/3.0/). 